\title{
DO FUTURES BENEFIT FARMERS?
}

Sergio H. Lence*

\begin{abstract}
Simulations are used to analyze welfare and market- and farm-level effects of making futures available to producers of a storable commodity. Key features of the model are the explicit consideration of dynamic impacts due to inventories, and of aggregate market effects associated with futures adoption by some producers. Application to the natural rubber market shows that futures availability can lead to sizeable market- and farm-level effects. Futures availability enhances consumer welfare, reduces non-adopter welfare, and yields important welfare gains for adopters when their market share is small and welfare losses when they account for a sufficiently large market share.
\end{abstract}

Keywords: Commodity markets, futures, natural rubber, rational expectations, storage model, welfare analysis.

JEL Codes: C61, G13, Q11, Q13.

Suggested Running Head: Do Futures Benefit Farmers?

*Sergio H. Lence is Professor and Marlin Cole Chair of International Agricultural Economics, Department of Economics, Iowa State University, Ames. The present work was initiated while he was a visiting scholar at the Economic and Social Department of the Food and Agriculture Organization (FAO) of the United Nations. The opinions expressed in this paper do not necessarily reflect the views of FAO.

Corresponding author: $\quad$ Sergio H. Lence 368E Heady Hall Iowa State University Ames, IA 50011-1070

Phone: 515-294-6644

Fax: 515-294-4545

Email: shlence@iastate.edu 


\section{DO FUTURES BENEFIT FARMERS?}

Vulnerability to risks is among the most important problems faced by commodity producers in developing economies (see Roumasset, Boussard, and Singh 1979) and developed economies (see Just and Pope 2001) alike. Concerns with price risk have led countries to adopt schemes intended to stabilize prices (Newbery and Stiglitz 1981). Similarly, governments have often underwritten crop insurance policies to curb producers' yield risks (Hazell, Pomareda, and Valdez 1986, Coble and Knight 2001).

Large-scale government-led price stabilization schemes have proven to be unsustainable (Gardner 1988, p. 303). For the specific case of the natural rubber market discussed later in the present article, Burger and Smit (2001) provide an account of the demise of the price support scheme originally set up by the International Natural Rubber Organization. Further, the adoption of such mechanisms in the future is likely to be hampered by agreements to liberalize agriculture under the auspices of the World Trade Organization (see World Trade Organization 2004). These facts may explain the recent interest in promoting the use of institutional markets, such as futures markets, to manage the price risks affecting commodity producers (United Nations Conference on Trade and Development, 1994 and 1998). An example of such interest is the International Task Force on Commodity Risk Management in Developing Countries (ITF) convened by the World Bank. The ITF includes international institutions, producer and consumer organizations, major commodity exchanges, and commodity trading firms (ITF 1999, Annex 5). Succinctly, the ITF has recommended facilitating the use of market-based riskmanagement instruments by developing country commodity producers (ITF 1999, Preface).

The promotion of futures and other similar tools to manage commodity producers' price risks is based on the assumption that they increase the well-being of their adopters. This assumption is valid from the standpoint of a single producer who adopts such tools, as he would not use them if they made him worse off. However, the assumption need not hold when many producers adopt risk-management tools simultaneously. This is true because the aggregation of 
individual responses may adversely affect the commodity market as a whole (e.g., spot prices may fall if hedging induces an increase in adopter output). The first theoretical studies to specifically address this issue in the context of forward (as opposed to futures) markets for storable commodities were Kawai (1983) and Britto (1984) for storable commodities, and Turnovsky (1983) for nonstorable commodities.

Conceptually, two approaches may be used to quantify the impact of futures on producer welfare, taking into account the aggregate effect of adopters' decisions on the market. The first approach is to perform econometric estimation with historical data. Unfortunately, this method is unlikely to have much power due to the high volatility of many of the series involved (e.g., price and output) and the likely existence of structural changes (e.g., changes in production technology) in the past. Further, it requires data that usually are not available (e.g., long time series on individual producers' behavior before and after adoption). Not surprisingly, there are no studies pursuing this line of research.

The second approach consists of building economic models of the market(s) under analysis in terms of "deep parameters," and simulating their behavior with and without futures markets. Otherwise, if some of the model's parameters depended on the policy regimes under consideration, the analysis would be subject to the famous "Lucas' critique" (Lucas 1976). Deep parameters are those unaffected by the policy intervention being studied. For example, weather variability is a deep parameter in the case of agricultural futures. In contrast, the variance of spot prices is not a deep parameter because it is endogenous, as it is affected by producers' optimal production responses to the availability of futures. Disadvantages of the simulation approach are that its results are model-specific, and that they apply to real-world problems only insofar as the latter are realistically represented by the underlying economic model. To the best of our knowledge, Turnovsky and Campbell (1985) is the only previous attempt to use the simulation approach to analyze the welfare effects of introducing a forward market for a storable commodity. Lence and Hayes (2002) resorted to the simulation approach to analyze U.S. farm programs, but they did not allow for futures trading. 
The main contributions of the present article are the incorporation of dynamics due to inventory effects and the consideration of the aggregate effects of futures adopters. The model is based on the rational storage paradigm (Williams and Wright 1991; Deaton and Laroque 1992, 1996; Chambers and Bailey 1996), and incorporates realistic features not considered in the two studies most closely related to the present one, namely, Turnovsky (1983) and Turnovsky and Campbell (1985). In particular, the proposed model involves futures rather than forward markets, allows for stockouts, does not rely on a mean-variance framework, and accounts for the fact that futures need not be made available to (or be adopted by) all producers. By allowing for nonadopters, we can quantify the changes in their optimal behavior and welfare induced by the other producers' adoption of futures.

In addition, we show how to apply the model for policy analysis purposes, by parameterizing it so as to represent the natural rubber market. Natural rubber is of practical interest because its price is volatile (ITF 2001), and the potential adoption of futures by natural rubber producers has attracted attention from academia (Zant 2001), as well as from the ITF (ITF 2001). Zant (2001) analyzed the impact of making hedging tools available in India. He showed that the welfare of India's natural rubber producers would increase substantially if hedging mechanisms were available. However, in calculating welfare effects, he took into account neither the market impact of the changes in farmers' output decisions induced by the hedging scheme, nor the dynamic effects that are central to the present study. The ITF (2001) analyzed the feasibility of offering price insurance tools to natural rubber growers in Thailand. The ITF study assumed that many of Thailand's natural rubber producers would greatly benefit from being able to reduce their price risks, but it did not attempt to quantify such welfare gains.

\section{A Theoretical Model for the Spot Market of a Storable Crop}

The present study focuses on the impact of making futures contracts available to some of the farmers who produce a storable crop. Such producers are labeled "adopters," and the rest of the 
farmers are referred to as "non-adopters." The total crop supply at date $t$ is given by total output plus carry-in storage $\left(I_{t}\right)$ :

(1) Total Crop Supply at Time $t=n_{A} q_{A, t}+n_{N} q_{N, t}+I_{t}$,

where $n_{A}\left(n_{N}\right)$ is the number of adopters (non-adopters), and $q_{A, t}\left(q_{N, t}\right)$ is the average output per adopting (non-adopting) farmer. The crop can be used to satisfy demand for current consumption $\left(C_{t}\right)$, or it can be purchased by speculators to store and resell in the future $\left(I_{t+1}\right)$. Market equilibrium at time $t$ requires that total supply be equal to total demand. That is,

$$
I_{t+1}=n_{A} q_{A, t}+n_{N} q_{N, t}+I_{t}-C_{t} \geq 0
$$

where the inequality in (2) follows from the fact that storage cannot be negative.

Solving for market equilibrium (2) requires specifying functional forms for the different components of market demand and supply. Such components are described next.

\section{Demand for Current Consumption}

Aggregate demand for current consumption $\left(C_{t}\right)$ is postulated to be of a standard isoelastic form:

$$
C_{t}=\delta_{0} P_{t}^{-\delta_{1}} \varepsilon_{C, t}
$$

where $P_{t}$ denotes the crop's world price at time $t, \delta_{0}>0$ is a scaling parameter, $\delta_{1}>0$ is the elasticity of demand for current consumption, and $\varepsilon_{C, t}>0$ is a random demand shock (e.g., a disturbance to income). Without loss of generality, the mean of the random shock is set equal to one $\left(\operatorname{Mean}\left(\varepsilon_{C, t}\right)=1\right){ }^{1}$ 


\section{Demand for Speculative Stocks}

Demand for speculative purposes is driven by the expectation of making profits from storage. Under perfect competition, speculators' (discounted) expected profits from buying one unit of the crop at time $t$, storing it, and selling it at $t+1$ must satisfy condition (4) in equilibrium:

$$
E_{t}\left(P_{t+1}\right) /(1+r)-P_{t}-\phi \leq 0
$$

where $E_{t}(\cdot)$ is the expectation operator conditional on information available at time $t, r$ denotes the interest rate, and $\phi$ represents the cost of storing one unit of the crop for one period. If (4) does not hold, speculators will buy more units of the crop at time $t$ with the purpose of selling them at time $t+1$, which is inconsistent with equilibrium.

When storage is expected to be unprofitable (i.e., $\left.\left[E_{t}\left(P_{t+1}\right) /(1+r)-P_{t}-\phi\right]<0\right)$, speculators will reduce their commodity holdings, thereby exerting downward pressure on current prices $P_{t}$ and causing an upward revision in the next-period's price expectations $E_{t}\left(P_{t+1}\right)$. However, such a process need not drive the left-hand side of (4) to zero because storage cannot be reduced below zero. It follows that equilibrium also implies that condition (5) must hold for speculative storage demand:

$$
\left[E_{t}\left(P_{t+1}\right) /(1+r)-P_{t}-\phi\right] \times I_{t+1}=0, I_{t+1} \geq 0
$$

Together, (4) and (5) define the demand for speculative storage (Deaton and Laroque 1992).

\section{Farmers' Supply in the Absence of Futures Markets}

Crop output is assumed to be the result of farmers' optimal decisions based on their underlying preferences and production technologies. Unfortunately, modeling heterogeneous populations of adopting and non-adopting farmers is intractable from a computational standpoint. Hence, the 
analysis relies upon the characterization of a representative adopter and a representative nonadopter.

For both adopters and non-adopters, the amount of crop produced by farmers of type $j$ at time $t\left(q_{j, t}\right)$ is equal to the product of farmers' planned output as of time $t-1\left(x_{j, t-1} \equiv E_{t-1}\left(q_{j, t}\right)\right)$ and a time-t output shock $\varepsilon_{q j, t}>0$ :

$$
q_{j, t}=x_{j, t-1} \varepsilon_{q j, t}
$$

for $j=A$ and $N$. By construction, the random output shock must have a mean equal to one $\left(\operatorname{Mean}\left(\varepsilon_{q j, t}\right)=E_{t-1}\left(\varepsilon_{q j, t}\right)=1\right){ }^{2}$ At time $t-1$, type-j farmers choose the level of planned output $x_{j, t-1}$ that maximizes the expected utility of their time-t profits $\pi_{j, t}=p_{j, t} x \varepsilon_{q j, t}-v_{j}(x)$ :

$$
x_{j, t-1} \equiv \operatorname{argmax}_{x}\left\{\mathrm{E}_{t-1}\left[U_{j}\left(p_{j, t} x \varepsilon_{q j, t}-v_{j}(x)\right)\right]\right\} .
$$

In (7), $U_{j}(\cdot), v_{j}(\cdot)$ denote, respectively, the von Neumann-Morgenstern utility function and the variable cost function of type-j farmers, and $p_{j, t}$ represents the local price received by producers of type $j$.

For numerical simulation purposes, the utility function is specialized to the constant absolute risk aversion (CARA) form $U_{j}(\pi)=-\exp \left(-\lambda_{j} \pi\right)$, where $\lambda_{j}$ is the coefficient of absolute risk aversion corresponding to type-j farmers. ${ }^{3}$ Similarly, the variable cost function is specialized to the power form $v_{j}(x)=\theta_{j, 0} x^{\theta_{j, 1}}$, where $\theta_{j, 0}>0$ is a scaling parameter, and $\theta_{j, 1}$ is the elasticity of cost with respect to planned output. ${ }^{4}$ Increasing marginal costs require $\theta_{j, 1}>1$; further, $\theta_{j, 1} \geq 2$ is necessary for marginal costs to rise at an increasing rate. Finally, the local price received by type- $j$ farmers is assumed to be stochastically linked to the world price with $p_{j, t}=P_{t} \varepsilon_{p j, t}$, where $\varepsilon_{p j, t}>0$ is a random shock. Shock $\varepsilon_{p j, t}$ represents the imperfections in the transmission of world prices to the local market of type-j farmers. 
Supply by Adopting Farmers when Futures Markets Are Available

Optimization problem (7) does not provide for futures trading, implicitly assuming that either futures markets are not available to adopting farmers, or futures trading costs are too high to make it optimal for farmers to participate in the futures markets. To analyze the impact of making futures available to adopters, a futures availability scenario is defined as one in which they can costlessly hedge using futures contracts. That is, at time $t-1$ adopting farmers may hedge their time-t crop output by selling $h_{A, t-1}$ units at the known futures price $F_{t-1}$, in which case at time $t$ they receive the amount $\left[\left(F_{t-1}-P_{t}\right) h_{A, t-1}\right]$. As a result of making futures available to adopters, their profits are defined as $\pi_{A, t}=p_{A, t} \times \varepsilon_{q A, t}-v_{A}(x)+\left(F_{t-1}-P_{t}\right) h_{A, t-1}$, and their expected utility maximization problem involves the optimal choice of both planned output $x_{A, t-1}$ and hedging level $h_{A, t-1}$ :

$$
\left[x_{A, t-1}, h_{A, t-1}\right]=\operatorname{argmax}_{x, h}\left\{E_{t-1}\left[U_{A}\left(p_{A, t} x \varepsilon_{q A, t}-v_{A}(x)+\left(F_{t-1}-P_{t}\right) h\right)\right]\right\} .
$$

Note that actual production is uncertain at the time of hedging it, and that the relevant price in the futures market is the world crop price $P_{t}$, as opposed to the local price $p_{A, t}$. The lesser the adopters' uncertainty about production and price-transmission shocks ( $\varepsilon_{q A, t}$ and $\varepsilon_{p A, t}$, respectively), the greater the potential is to reduce their risks by hedging.

When crop futures are available to adopters, solving the model requires specifying the mechanism by which futures prices are formed. For this purpose, futures prices are assumed to be equal to the conditional expectation of the next period's world prices:

$$
F_{t-1}=E_{t-1}\left(P_{t}\right)
$$

Condition (9) rules out the possibility of adopting farmers trading futures for speculative purposes. That is, (9) implies that the only incentive for adopters to trade futures contracts is to hedge their exposure to price risk. This is a desirable restriction, given the present study's aim of 
analyzing the effect of futures availability associated with their usage as risk management tools, as opposed to their utilization as instruments for speculation. Otherwise, adopting farmers could be made arbitrarily better off if allowed to trade in futures to exploit (expected) speculative profitable opportunities.

\section{Expectations and Crop Market Equilibrium}

As pointed out earlier, market equilibrium at time $t$ requires (2) to hold. Given the planned output decisions made by farmers at $t-1\left(x_{A, t-1}\right.$ and $\left.x_{N, t-1}\right)$ and the actual output shocks at $t\left(\varepsilon_{q A, t}\right.$ and $\varepsilon_{q N, t}$ ), time-t actual production is obtained from (6). Actual output plus the storage decision made by speculators at $t-1\left(I_{t}\right)$ determine total supply at $t$, as shown in (1). That is, total supply at $t$ is determined by agents' decisions made at $t-1$ and by date-t output shocks. Given the date- $t$ current consumption shock $\varepsilon_{C, t}$ and expectations about the next-period's price $E_{t}\left(P_{t+1}\right)$, the current price $P_{t}$ must adjust so that demand for current consumption and speculative storage satisfy equilibrium condition (2).

Clearly, the equilibrium values of current consumption, world prices, and ending stocks $\left(C_{t}^{e q}, P_{t}^{e q}\right.$, and $I_{t+1}^{e q}$, respectively) are affected by the current expectations about next-period's world price $E_{t}\left(P_{t+1}\right)$, because speculative storage demand (i.e., (4) and (5)) is a function of $E_{t}\left(P_{t+1}\right)$. Furthermore, the next period's equilibrium values (i.e., $C_{t+1}^{e q}, P_{t+1}^{e q}$, and $\left.I_{t+2}^{e q}\right)$ are functions of the entire probability distribution of the next-period's world price and the output and price-transmission shocks, conditional on the current information. This is true because the next-period's actual output $\left(q_{j, t+1}\right)$ depends on the planned output level chosen in the current period $\left(x_{j, t}\right)$ so as to maximize expected utility (7). Hence, the market equilibrium cannot be solved for unless one specifies how farmers and speculative storers form their expectations.

Here, decision makers are assumed to be rational, in the sense that their subjective expectations of the random variables are equal to the objective expectations of such variables implied by the model. As in Newbery and Stiglitz (1981, ch. 10), the reasons for postulating rational expectations are threefold. First, from a practical standpoint, hypothesizing non-rational 
expectations poses a significant challenge. This is true because there is an infinite number of ways in which expectations can be rendered non-rational, and one would be forced to arbitrarily choose one from among them. Second, from an analytical perspective, assuming rational expectations allows one to focus on the benefits of futures for adopters, arising from their usage as a risk-management tool, rather than from their potential to yield informational gains. For example, if storers did not have rational price expectations, they could obtain informational gains without having to trade futures contracts, by choosing optimal storage levels based on futures prices instead of their own (irrational) price expectations. Finally, rational expectations, together with (9), eliminate the possibility of obtaining arbitrarily large (expected) speculative gains by exploiting informational inefficiencies in the futures market.

\section{Welfare Analysis}

Welfare analysis requires the explicit consideration of agents' utilities with and without futures, and of the corresponding changes in the equilibrium probability density functions (pdfs) of the endogenous variables. Here, the welfare effects caused by the availability of futures are measured by means of compensating incomes.

To see how the compensating income of adopting farmers $\left(\bar{Y}_{A}\right)$ is calculated, consider two thought experiments. In experiment 1, futures are not available before random time $t$, but starting at that time they are made available to adopters forever. In experiment 2 , the scenario is similar to that of experiment 1 , with the difference that starting at time $t$ adopters are given a certain amount of income $Y_{A}$ in each period, forever, instead of allowing them to trade in futures. Define scalars $\bar{U}_{A}$ and $\overline{\bar{U}}_{A}\left(Y_{A}\right)$ as adopters' unconditional expected utility under experiments 1 and 2, respectively. ${ }^{5}$ The certain per-period income $\bar{Y}_{A}$ defined by the equality $\bar{U}_{A}=\overline{\bar{U}}_{A}\left(\bar{Y}_{A}\right)$ represents the amount that makes adopters indifferent between using and not using futures.

The effect of futures availability on non-adopting farmers can be similarly measured by non-adopters' compensating income $\left(\bar{Y}_{N}\right)$. It is worth pointing out that $\bar{Y}_{N}$ only includes compensation for the pdf changes induced by adopters' use of futures, as non-adopters never 
trade futures by construction. In contrast, $\bar{Y}_{A}$ involves compensation for such pdf changes, as well as for preventing adopters from employing futures.

To measure consumer compensating income $\left(\bar{Y}_{C}\right)$, note that demand schedule (3) can be derived by assuming a representative consumer characterized by the quasilinear utility function $U_{C}\left(C_{t}, Z_{t}\right) \equiv \delta_{0}^{1 / \delta_{1}} C_{t}^{1-1 / \delta_{1}} /\left(1-1 / \delta_{1}\right)+Z_{t}$ subject to the budget constraint $W_{t}=P_{t} C_{t}+P_{Z, t} Z_{t}$, where $Z_{t}$ denotes a composite good, $P_{Z, t}$ is its price, and $W_{t}$ is the consumer's wealth. Using the budget constraint to obtain $Z_{t}=W_{t} / P_{Z, t}-P_{t} / P_{Z, t} C_{t}$, and plugging the resulting expression into the utility function to get $U_{C}\left(C_{t}, W_{t} / P_{Z, t}-P_{t} / P_{Z, t} C_{t}\right) \equiv \delta_{0}^{1 / \delta_{1}} C_{t}^{1-1 / \delta_{1}} /\left(1-1 / \delta_{1}\right)+W_{t} / P_{Z, t}-P_{t} / P_{Z, t} C_{t}$, the first-order necessary condition (FOC) corresponding to optimal commodity consumption is $\partial U_{C}^{*} / \partial C_{t}=\delta_{0}^{1 / \delta_{1}} C_{t}^{*-1 / \delta_{1}}-P_{t} / P_{Z, t}=0$. It is straightforward to derive demand function (3) from the FOC by letting $\varepsilon_{C, t} \equiv P_{Z, t}^{\delta_{1}}$. Further, by plugging the FOC back into the utility function and rearranging, consumer surplus can be expressed as $U_{C}\left(C_{t}^{*}, W_{t} / P_{Z, t}-P_{t} / P_{Z, t} C_{t}^{*}\right) \equiv \delta_{0}^{1 / \delta_{1}}$ $C_{t}^{* 1-1 / \delta_{1}} /\left(\delta_{1}-1\right)+W_{t} / P_{Z, t \cdot}$. Therefore, consumer compensating income is computed as $\bar{Y}_{C}=\overline{\bar{U}}_{C}-$

$\bar{U}_{C}$, where $\overline{\bar{U}}_{C}$ and $\bar{U}_{C}$ represent mean consumer surplus under thought experiments 1 and 2 , respectively. Like $\bar{Y}_{N}, \bar{Y}_{C}$ only measures compensation for the pdf changes induced by the adopting farmers' use of futures.

\section{Numerical Methods}

To analyze the behavior of equilibrium endogenous variables (e.g., prices) in the model introduced in the preceding section, one must first solve for the market equilibrium conditions under each possible state of the world. This is not a trivial task, because the model has no closedform solution and is highly nonlinear. Here, the model is solved using the method developed by Williams and Wright (Judd 1998, ch. 12 and 17). The essence of this method consists of estimating the function $\hat{\Psi}(\cdot)$ that approximates the price expectation conditional on information at time $t$ as a function of time-t carry-over storage, i.e., $E_{t}\left(P_{t+1}\right)=\Psi\left(I_{t+1}\right)$. The rationale for the latter equality is that $E_{t}\left(P_{t+1}\right)$ can only depend on information available at time $t$, and current optimal storage $I_{t+1}$ must incorporate all such information. 
The computer algorithm is sketched in Williams and Wright (1991, ch. 3). Cubic splines

are used for the function approximant $\hat{\Psi}(\cdot)$, and the pdfs of the exogenous random shocks are approximated by Gaussian quadrature (Judd 1998). The cubic spline interpolation used is based on 63 nodes, which are more densily distributed over the range where $\hat{\Psi}(\cdot)$ exhibits the greatest nonlinearities in order to achieve greater accuracy. The Gaussian quadrature scheme relies on three nodes for each exogenous random variable. The number of nodes is chosen to obtain an acceptable level of accuracy, while maintaining computational feasibility. The cubic spline interpolation and Gaussian quadrature schemes are calculated by means of the programming language MATLAB version 7.0, using the computer routines developed by Miranda and Fackler.

\section{Model Parameterization}

The postulated model is highly stylized, as it is intended to capture key features common to agricultural commodity markets in general. For policy analysis, however, the model is most useful when parameterized to represent specific market scenarios. To demonstrate how it can be used to draw inferences about the effects of adopting futures, we have set its parameter values so as to simulate the natural rubber market. Parameter values corresponding to the natural rubber market can be obtained from previous studies or calibrated to match key measures reported in the literature.

The parameterization used to represent the natural rubber market, as well as the sources it is based on, are reported in table 1 . The values for the scaling parameters $\left(n_{A}, n_{N}, \delta_{0}, \theta_{A, 0}\right.$, and $\left.\theta_{N, 0}\right)$ and the means of the exogenous price-transmission shocks $\left(\operatorname{Mean}\left(\varepsilon_{p A, t}\right)\right.$ and $\left.\operatorname{Mean}\left(\varepsilon_{p N, t}\right)\right)$ are assigned so as to scale the units of measurement of the present system of equations around the unit value. This is achieved by setting $\delta_{0}=\operatorname{Mean}\left(\varepsilon_{p A, t}\right)=\operatorname{Mean}\left(\varepsilon_{p N, t}\right)=1, \theta_{A, 0}=1 / \theta_{A, 1}$, and $\theta_{N, 0}=$ $1 / \theta_{N, 1}$, and by scaling the numbers of adopting and non-adopting farmers so that $n_{A}+n_{N}=1$. Scaling enhances the accuracy of the numerical solutions by avoiding the computation of variables whose orders of magnitude are substantially different (Judd 1998, ch. 2). The advocated scaling implies that the equilibrium values of adopter output, non-adopter output, 
current consumption, and prices all equal one when all exogenous random variables are fixed at their mean values for all dates $t$. That is, if all exogenous random variables were fixed at their mean values at all times, equilibrium in the scaled model would be characterized by $q_{A, t}=q_{N, t}=$ $C_{t}=P_{t}=p_{A, t}=p_{N, t}=1$ for all $t$. In such non-stochastic equilibrium, total output would also equal one ( $n_{A} q_{A, t}+n_{N} q_{N, t}=1$ for all $\left.t\right)$, and storage would be zero (i.e., $I_{t+1}=0$ for all $\left.t\right)$. Besides being important for improving numerical accuracy, scaling has the advantage of facilitating the interpretation of results. For example, the results in tables 2 through 4 correspond to stochastic scenarios. Hence, comparing them with the non-stochastic benchmark allows one to easily infer the impact of introducing randomness into the system.

Following Zant (2001), the observation period (i.e., the time elapsed between $t$ and $t+1$ ) for the simulations is set equal to three months. The values used for the elasticity of demand $\left(\delta_{1}\right.$ $=0.25)$, the coefficient of absolute risk aversion $\left(\lambda_{j}=4.7\right)$, the elasticity of production $\operatorname{costs}\left(\theta_{j, 1}\right.$ $=2)$, the quarterly variable storage costs $(\phi=0.009)$, and the quarterly interest rate $(r=0.015)$ are consistent not only with the natural rubber market, but also with the values used in studies of other agricultural commodities. For example, Newbery and Stiglitz (1981, p. 295) and Williams and Wright (1991, p. 38) use annual storage costs of $\phi=0.02$, and the coefficient of relative risk aversion of 3.1 implied by $\lambda_{j}=4.7$ is well within the range considered typical by Gollier (2001, pp. 31 and 289) and Kocherlakota (1996).

The exogenous random shocks $\left(\varepsilon_{C, t}, \varepsilon_{q j, t}\right.$, and $\left.\varepsilon_{p j, t}\right)$ are assumed to be independently and identically log-normally distributed because they must be positive. The standard deviations (StDs) of the exogenous random shocks represent the respective coefficients of variation $(C V s)$, as well, because their means equal one. $\operatorname{StD}\left(\varepsilon_{C, t}\right)=C V\left(\varepsilon_{C, t}\right)=0.158$ is the only figure not taken from previous studies, but is the value required for the simulations to yield $C V\left(P_{t}\right)=23 \%$, which is the $\mathrm{CV}$ of the world price of natural rubber implied by the data in Zant (2001, p. 709). $C V\left(P_{t}\right)$ $=23 \%$ is consistent historical values for agricultural commodities in general (see Newbery and Stiglitz 1981, p. 291). 
For the simulations representing the case of futures being adopted by relatively few

farmers, the numbers of adopters and non-adopters are set at $n^{A}=0.1$ and $n^{N}=0.9$, respectively. In other words, such simulations assume that adopters account for $10 \%$ of world output. In the case of natural rubber, Thailand, Indonesia, Malaysia, and India are the top four producing countries and account for approximately $33 \%, 24 \%, 13 \%$, and $8 \%$, respectively, of world output (FAO). Hence, the low-adoption scenario would be similar to having producers in India or Malaysia adopt futures. The alternative scenario of a relatively widespread adoption of futures is run by employing $n^{A}=0.75$ and $n^{N}=0.25$. This case of a $75 \%$ market share corresponding to adopters would be comparable to having futures adopted by natural rubber producers in all top four producing countries (i.e., Thailand, Indonesia, Malaysia, and India).

\section{Results and Discussion}

The simulations provide insights on the impact of futures adoption at two different levels, namely, the effect on the world market for the crop, and the influence on the behaviors of adopters and non-adopters. Both levels of analysis are relevant, but they are conceptually different. Hence, they are addressed separately in the next subsections.

\section{Market Effects}

Steady-state results regarding market-level effects are summarized in table 2. The table reports the means, standard deviations, medians, and the $5 \%$ and $95 \%$ quantiles of the endogenous market variables under alternative scenarios. The second (fourth) column shows results for the futures-availability scenario assuming a small (large) share of adopters. For example, the "World Price" figures in the first column indicate that when futures are not available and $n_{A}=0.1$, the unconditional distribution of world prices has a mean of 1.165 , a standard deviation of 0.270 , a median of 1.115, and a 5\% (95\%) quantile of 0.962 (1.430). According to the corresponding figures in the second column, making futures available induces reductions in the mean, standard deviation, median, and $5 \%$ and $95 \%$ quantiles of $0.4 \%$ (from 1.165 to 1.160 ), $2.2 \%$ (from 0.270 
to 0.264 ), $0.4 \%$ (from 1.115 to 1.111 ), $0.1 \%$ (from 0.962 to 0.961 ), and $1.3 \%$ (from 1.430 to $1.411)$, respectively.

Recall that the scaling adopted for the simulations implies that in the non-stochastic benchmark scenario, total output, total supply, total consumption, price, and consumption expenditures all equal unity, and storage is zero. Hence, the first and third columns in table 2 show that the introduction of randomness into the non-stochastic economy reduces mean output and consumption by $3.3 \%$, while increasing total supply by slightly over $40 \%$. The latter occurs because mean storage increases from zero to almost $50 \%$ of mean output. In addition, random exogenous shocks cause the mean (median) world price to go up by approximately $17 \%(12 \%)$, and mean (median) consumption expenditures to rise by about $12 \%(8.5 \%)$. In the case of total supply, storage, prices, and consumption expenditures, there are substantial differences between means and medians, as well as noticeable asymmetries in the location of the $5 \%$ and $95 \%$ quantiles indicative of pdfs strongly skewed to the right. In other words, supply, storage, prices, and consumption expenditures tend to be at relatively low levels most of the time, but on a few occasions they achieve quite high magnitudes. In contrast, the pdfs of current consumption are slightly skewed to the left, and the pdfs of total output are essentially symmetric.

Turning to the market-level changes induced by the availability of futures, it is apparent from the comparison of the first and second columns of table 2 that such changes are modest but not necessarily negligible, even when the market share of adopters is as small as $10 \%$. When $n_{A}$ $=0.1$, futures availability reduces the means of total supply, storage, prices, and consumption expenditures by $0.2 \%, 0.9 \%, 0.4 \%$, and $0.3 \%$, respectively, but increases the means of both total output and consumption by $0.1 \%$. Futures availability also reduces the standard deviations of total supply, consumption, storage, prices, and consumption expenditures by $0.6 \%, 1.6 \%, 0.6 \%$, $2.2 \%$, and $2.1 \%$, respectively, but increases the standard deviation of output by $1 \%$.

Comparison of the second and fourth columns of table 2 reveals that futures availability exerts the same qualitative effects when the share of adopters is large $\left(n_{A}=0.75\right)$ as when that share is small $\left(n_{A}=0.1\right)$. However, in percentage terms, the magnitudes of the changes in means 
and standard deviations induced by futures availability in the large-adopter-share scenario are approximately five times the ones corresponding to the small-adopter-share scenario. For $n_{A}=$ 0.75, making futures available causes the means of total supply, storage, prices, and consumption expenditures to decline by $1.1 \%, 4.6 \%, 2.4 \%$, and $1.8 \%$, respectively, and the means of both total output and consumption to increase by $0.5 \%$. As a result of futures adoption, the standard deviations of total supply, consumption, storage, prices, and consumption expenditures fall by $3.5 \%, 8.3 \%, 3.2 \%, 11.2 \%$, and $10.4 \%$, respectively, and the standard deviation of output goes up by $9.3 \%$. These findings indicate that the market-level effects induced by a large proportion of producers adopting futures can be substantial.

\section{Effects on the Behaviors of Adopters and Non-Adopters}

Farm-level results corresponding to adopters and non-adopters are shown in tables 3 and 4 , respectively. Data in these tables are reported in the same format as in table 2. The numbers in tables 3 and 4 can also be interpreted in relation to the equilibrium values corresponding to exogenous shocks fixed at their mean values for all periods. For example, the first column of table 3 shows that for $n_{A}=0.1$, the existence of exogenous random shocks causes adopters to reduce the means of planned and actual output by $4.1 \%$ (from 1 to 0.959 ), while increasing mean profits by $32.6 \%$ (from 0.5 to 0.663 ). ${ }^{6}$

Table 3 demonstrates that the farm-level impact of futures availability on adopters is substantial, regardless of whether they account for a small or a large share of total output. Futures availability causes the means of planned and actual output to increase by $3.3 \%$ (from 0.959 to 0.991 ) when $n_{A}=0.1$, and by $1.2 \%$ (from 0.967 to 0.978 ) when $n_{A}=0.75$. In addition, when adopters are allowed to hedge, their production plans become considerably more responsive to expected market conditions. For $n_{A}=0.1(0.75)$, this is reflected in a standard deviation of planned output that is $56.9 \%(27.0 \%)$ higher when futures are available, even though the standard deviation of local prices is $1.6 \%(8.1 \%)$ smaller. Adopters hedge a substantial proportion of their planned output if allowed to do so. The mean hedge equals $82 \%$ 
$(68.4 \%)$ of the mean planned output when $n_{A}=0.1(0.75)$. When the adopters' share is large, their hedge is noticeably smaller due to the greater effectiveness of the "natural" hedge (i.e., the hedge induced by the negative response of world prices to the output shocks experienced by adopters).

The increase in the level and responsiveness of output by adopters causes a reduction in the mean and the standard deviation of the world price (see table 2), which in turn implies a smaller mean and standard deviation for the local price (e.g., for $n_{A}=0.75$, they fall from 1.167 and 0.334 to 113.9 and 0.307 , respectively). As a result, futures availability is associated with slightly larger mean total profits when adopter share is small ( 0.665 compared to 0.663$)$, but lower mean total profits when adopter share is large (0.639 compared to 0.664$)$. Regardless of the market share accounted for by adopting farmers, hedging greatly reduces the standard deviation of adopters' total profits (from 0.345 to 0.269 for $n_{A}=0.1$, and from 0.332 to 0.243 for $\left.n_{A}=0.75\right)$.

The results reported in table 4 indicate that the availability of futures to adopters also impacts non-adopters' farm-level endogenous variables, even if the market share of adopting farmers is as small as $10 \%$. The availability of futures to adopters induces a leftward shift in the pdfs of non-adopters' planned output, actual output, local price, and profits, as well as a reduction in their standard deviations. In response to adopters' use of futures, non-adopters reduce average planned output by $0.3 \%$ (from 0.967 to 0.964 ) when $n_{A}=0.1$, and by $1.3 \%$ (from 0.962 to 0.949 ) when $n_{A}=0.75$. At the same time, the standard deviation of planned output falls by $2.6 \%$ (from 0.057 to 0.055 ) and $13.2 \%$ (from 0.053 to 0.046 ) when adopters' shares are small and large, respectively. The latter effect is a consequence of lower price volatility, as futures availability reduces the standard deviation of local prices from 0.336 to 0.330 when $n_{A}=0.1$, and from 0.334 to 0.307 when $n_{A}=0.75$.

Given the smaller mean output and the lower mean price received by non-adopters, it is not surprising that their mean profits fall (from 0.662 to 0.656 and from 0.665 to 0.634 when adopters have small and large market shares, respectively) as futures become available. Futures 
availability is also associated with a reduction in the standard deviation of non-adopter profits (from 0.330 to 0.324 when $n_{A}=0.1$, and from 0.341 to 0.307 when $n_{A}=0.75$ ), which stems mostly from the declines in the standard deviations both of prices and planned output.

\section{Effects on Welfare}

Welfare is ultimately a function of the level, volatility, and higher moments of the endogenous pdfs. From the results reported in table 2 , it seems sensible to infer that consumers gain by making futures available to producers, as mean consumption increases, mean consumption expenditures decreases, and the standard deviations of both consumption and consumption expenditures fall. The plot of consumer compensating income $\left(\bar{Y}_{C}\right)$ depicted in figure 1 confirms this intuition. Consumer compensating income is $\bar{Y}_{C}=0.005$ when $n_{A}=0.1$, and $\bar{Y}_{C}=0.027$ when $n_{A}=0.75$. Such gains amount to $0.4 \%$ and $2.4 \%$, respectively, of mean consumption expenditures before adoption.

Figure 1 shows that consumer compensating income is always positive and monotonically increasing with the market share of adopting farmers. Consumer compensating income tends to zero as $n_{A} \rightarrow 0$, because in such an instance the share of adopters is so small that their use of futures does not change the equilibrium pdfs of the market-level endogenous variables. The larger the proportion of adopters, the larger their impact on equilibrium pdfs and, consequently, the greater their effect on consumer compensating income. At the extreme, where all producers adopt futures $\left(n_{A}=1\right)$, consumer compensating income equals $\bar{Y}_{C}=0.031$, or $2.8 \%$ of the mean consumption expenditures before adoption.

Figure 1 depicts producer compensating incomes, as well. It is clear from the graph that non-adopters lose as a result of making futures available to adopters. Non-adopter compensating variation equals $\bar{Y}_{N}=-0.003(-0.015)$ when $n_{A}=0.1(0.75)$, which amounts to $0.4 \%(2.2 \%)$ of non-adopters' mean profits when futures are not available. Figure 1 also shows that the negative impact of futures availability on non-adopter welfare increases monotonically with the market share of adopters. The polar case of a negligible number of adopters $\left(n_{A} \rightarrow 0\right)$ yields no welfare 
losses for non-adopting farmers. This result is to be expected because, as mentioned earlier, $\bar{Y}_{N}$ measures only the compensation for the pdf changes induced by the adoption of futures, and pdfs remain essentially unaltered if adopters account for a negligible market share. At the other polar case, where virtually all producers are adopters $\left(n_{A} \rightarrow 1\right)$, futures availability induces a very large change in equilibrium pdfs. In turn, such change involves a welfare loss equivalent to $2.6 \%$ of non-adopters' mean profits when futures are not available $\left(\bar{Y}_{N}=-0.017\right)$ for the few farmers who do not adopt.

Figure 1 shows that futures availability is associated with welfare gains for adopters if their market share is below $n_{A}=0.71$, and with welfare losses otherwise. Further, adopters' welfare gains (losses) decrease (increase) monotonically with their market share. For the $n_{A}=0.1$ and $n_{A}=0.75$ scenarios reported in table 3 , adopters' compensating incomes are $\bar{Y}_{A}=0.016$ and $\bar{Y}_{A}=-0.001$, respectively. In terms of adopters' mean profits when futures are not available, such figures represent a gain of $2.5 \%$ and a loss of $0.1 \%$, respectively. Although it seems counterintuitive to have an expanded choice set (i.e., allowing for hedging) yielding a welfare loss, such a result is possible because of the combined assumptions of perfect competition and market clearing. Due to perfect competition, it is in each individual adopter's best interest to hedge and to modify his output decisions accordingly. However, the collective impact of such decisions on the market renders every adopting farmer worse off when the share of adopters is sufficiently large (i.e., when $n_{A}>0.71$ ).

In summary, the availability of futures affects the welfare of adopting producers both at the individual and the collective levels. At the individual level, futures allow each adopter to better hedge his risks. At the collective level, futures availability affects the equilibrium price pdf because of the changes in output decisions induced by hedging. The extreme case of $n_{A} \rightarrow 0$ represents the situation where adopters account for a negligible share of the market, in which case there is no collective effect from the adoption of futures. Hence, the value of $\bar{Y}_{A}=0.020$ for $n_{A} \rightarrow 0$ represents the welfare impact solely due to the enhanced adopters' decisions associated with the availability of futures. As the market share of adopters goes up, however, the collective 
effect becomes increasingly important. In the presence of an inelastic world demand, the rise in adopter output induced by the availability of futures tends to reduce mean profits for adopters as their market share increases. Futures availability also makes adopters more responsive to market conditions, which reduces the standard deviation of prices as the adopters' market share grows. Overall, however, when the adopter market share is sufficiently large (i.e., $n_{A}>0.71$ ), the negative welfare impact due to the reduction in mean prices outweighs the positive welfare impact from the individual effect and the reduced standard deviation of prices.

For completeness, figure 1 also depicts aggregate producer compensating income, obtained by weighing the compensating incomes of adopters and non-adopters by their respective market shares (i.e., $n_{A} \bar{Y}_{A}+n_{N} \bar{Y}_{N}$ ). The graph shows that futures availability unambiguously makes farmers as a whole worse off, the more so the larger the market share of adopters. However, consumer compensating income is positive and large enough to compensate for producer welfare losses and yield a net gain in welfare for society as a whole. Further, societal welfare gains increase monotonically with the number of adopting farmers.

\section{Concluding Remarks}

Recent years have brought a renewed interest in market-based solutions to alleviate some of the risks faced by commodity producers. However, to date, little has been done in terms of concomitant research. The present study aims at partially filling this gap by showing how to use a simulation approach to analyze the market-level effects of making a futures market available to producers of a storable commodity, as well as the impacts of this on producer behavior and consumer and producer welfare. Key features of the proposed model are the explicit consideration of dynamic impacts due to inventories, and of aggregate market effects associated with the adoption of futures by a group of producers.

The advocated model is applied to analyze the impact of making futures available to natural rubber producers. It is found that the market-level changes induced by the availability of futures are modest, but not negligible, if the adopters' market share is small, and that some of 
such changes can be noticeable if the proportion of producers adopting futures is large. The effect of futures availability is greater on the standard deviation than on the means of the marketlevel endogenous variables.

Futures availability clearly impacts adopters' farm-level variables, regardless of whether adopters account for a small or a large share of total output. The availability of futures also impacts the behavior of non-adopters, even if the market share of adopting farmers is relatively small. In terms of welfare, consumers clearly benefit from the adoption of futures by producers. The change in consumer welfare is always positive and monotonically increasing with the market share of adopting farmers. Non-adopters always lose when futures are made available to adopters. Such a loss increases monotonically with the proportion of adopters, and is sizeable if most producers adopt futures. Futures availability is associated with noticeable welfare gains for adopters when their market share is small, and with losses when they account for a sufficiently large portion of the market. On the aggregate, futures availability unambiguously makes farmers worse off, the more so the larger the market share of adopters. For society as a whole, however, futures availability yields a net gain because consumer gains outweigh producer losses, and such societal net gains increase as adoption becomes more widespread.

Overall, our findings suggest that there is no basis for advocating the use of futures as a means to improve commodity producers' well-being. The reasons for this assertion are that producers as a whole lose from making futures available and, more importantly, that futures availability reduces welfare even for adopters, provided the market share of the latter is sufficiently large.

From a policy perspective, the present study raises interesting issues. One of them is that measuring the success of a policy aimed at making futures available to improve producer welfare by the extent of adoption is likely to be misleading. This is true because our results suggest that adopter welfare decreases monotonically with the share of adopters. Another issue is associated with the finding that futures availability enhances consumer welfare, but reduces aggregate producer welfare. When coupled with the fact that many agricultural commodities tend to be 
produced in developing countries and consumed in developed economies, this implies that the push by international organizations (e.g., ITF) to improve the availability of futures among producers may ultimately enhance the lot of consumers in developed economies, while reducing the welfare of producers in developing countries. To many, this regressive redistributional outcome is likely to be both surprising and undesirable.

Under suitable modifications, the modeling framework presented here could be applied to analyze other important situations involving risks, such as yield insurance or revenue insurance contracts. As with any theoretical construct, the usefulness of the model for policy analysis depends on the realism of its underlying assumptions. In this regard, is important to note that our model is subject to William's criticism, in that it does not “... include imperfect spot and forward markets, long-term relationships as an enforcement mechanisms, prices not indicated to the public, prices that in any case anticipate later disputes about delivery conditions, grade, and payment" (Williams 2001, p. 759). It remains for future work to determine whether incorporating such features can substantially alter the present conclusions. Making the present model more realistic without rendering it computationally intractable constitutes an interesting research challenge. 


\section{Notes}

1. $\delta_{0}=\underline{\delta}_{0}$ and $\operatorname{Mean}\left(\varepsilon_{C, t}\right)=1$ is equivalent to setting $\delta_{0}=\underline{\delta}_{0} / y$ and $\operatorname{Mean}\left(\varepsilon_{C, t}\right)=y$ for any $y>0$. 2. Since $x_{j, t-1} \equiv E_{t-1}\left(q_{j, t}\right)=E_{t-1}\left(x_{j, t-1} \varepsilon_{q j, t}\right)=x_{j, t-1} E_{t-1}\left(\varepsilon_{q j, t}\right)$, it must be the case that $E_{t-1}\left(\varepsilon_{q j, t}\right)=1$. $\operatorname{Mean}\left(\varepsilon_{q j, t}\right)=1$ then follows immediately by application of the law of iterated expectations. 3. The analysis by Černý (2004) implies that the results from the present model should be robust to changes in the specification of the utility function, as long as the levels of relative risk aversion (defined as $-\pi U^{\prime \prime}(\pi) / U^{\prime}(\pi)$ ) are kept similar and the risks involved are neither too large nor too asymmetric.

4. As for utility, results should not be sensitive to modifications in the production function, provided the levels of $x v^{\prime}(x) / v^{\prime \prime}(x)$ are about the same and the risks are neither very large nor very skewed.

5. It should be clear that $\bar{U}_{A}$ is obtained by using the no-futures pdf, as experiment 2 prevents producers from using futures. In contrast, computation of $\overline{\bar{U}}_{A}\left(Y_{A}\right)$ involves the no-futures pdf for dates before $t$, and the pdf corresponding to the futures-availability scenario for dates $t$ and after. 6. In the nonstochastic equilibrium, $\pi_{A, t} \equiv p_{A, t} q_{A, t}-v_{A}\left(x_{A, t-1}\right)=1 \times 1-v_{A}(1)=0.5 \forall t$ because $\left[p_{A, t}, x_{A, t-1}, q_{A, t}\right]=[1,1,1] \forall t$. 


\section{References}

Burger, K., and H. P. Smit. 2001. "International Market Responses to the Asian Crises for Rubber, Cocoa and Coffee." In Gérard, F. and F. Ruf, eds. Agriculture in Crisis: People, Commodities and Natural Resources in Indonesia, 1996-2000. Richmond, UK: Curzon Press, pp. 31-48.

Britto, R. 1984. “The Simultaneous Determination of Spot and Futures Prices in a Simple Model with Production Risk.” Quarterly Journal of Economics 99:351-365.

Černý, A. 2004. Mathematical Techniques in Finance - Tools for Incomplete Markets. Princeton, NJ: Princeton University Press.

Chambers, M. J., and R. E. Bailey. 1996. “A Theory of Commodity Price Fluctuations.” Journal of Political Economy 104:924-957.

Coble, K. H., and T. O. Knight. 2001. "Crop Insurance as a Tool for Price and Yield Risk Management.” In Just, R. E., and R. D. Pope, eds. A Comprehensive Assessment of the Role of Risk in U.S. Agriculture. Boston: Kluwer Academic Press, ch. 20, pp. 445-468.

Deaton, A., and G. Laroque. 1996. "Competitive Storage and Commodity Price Dynamics." Journal of Political Economy 104:896-923.

_. 1992. "On the Behavior of Commodity Prices.” Review of Economic Studies 59:1-23.

Gardner, B. L. 1987. The Economics of Agricultural Policies. New York, NY: Macmillan Publishing Company.

Geweke, J. 1988. "Antithetic Acceleration of Monte Carlo Integration in Bayesian Inference." Journal of Econometrics 38:73-90.

Gollier, C. 2001. The Economics of Risk and Time. Cambridge, MA: The MIT Press.

Hazell, P., C. Pomareda, and A. Valdes, eds. 1986. Crop Insurance for Agricultural Development: Issues and Experience. Baltimore, MD: Johns Hopkins University Press for the International Food Policy Research Institute.

International Task Force on Commodity Risk Management in Developing Countries (ITF). 1999. "Dealing with Commodity Price Volatility in Developing Countries: A Proposal for a 
Market-Based Approach.” Discussion Paper for the Roundtable on Commodity Risk Management in Developing Countries at the Headquarters of the World Bank, Washington, D.C., 24 September. Available at http://www.itfcommrisk.org/itf.asp?page $=8$ (accessed September 5, 2007). . 2001. "Thailand Rubber Price Risk Management, Phase 2 Report.” Available at http://www.itf-commrisk.org/documents/thailandrubber2.pdf (accessed September 5, 2007).

Judd, K. L. 1998. Numerical Methods in Economics. Cambridge, MA: The MIT Press.

Just, R. E., and R. D. Pope, eds. 2001. A Comprehensive Assessment of the Role of Risk in U.S. Agriculture. Boston: Kluwer Academic Press.

Kawai, M. 1983. "Spot and Futures Prices of Nonstorable Commodities under Rational Expectations.” Quarterly Journal of Economics 98:235-254.

Kocherlakota, N. 1996. “The Equity Premium: It’s Still A Puzzle.” Journal of Economic Literature 34:42-71.

Lence, S. H., and D. J. Hayes. 2002. "U.S. Farm Policy and the Variability of Commodity Prices and Farm Revenues.” American Journal of Agricultural Economics 84:335-351.

Lucas, R. E., Jr. 1976. “Econometric Policy Evaluation: A Critique.” Carnegie-Rochester Conference Series in Public Policy 1:19-46.

Miranda, M., and P. Fackler. Computational Methods in Economics - MATLAB Toolbox. Available at http://www4.ncsu.edu/ pfackler/compecon/toolbox.html (accessed September 5, 2007).

Newbery, D. M. G., and J. E. Stiglitz. 1981. The Theory of Commodity Price Stabilization - A Study in the Economics of Risk. New York: Oxford University Press.

Priyadarshan, P. M., T. T. T. Hoa, H. Huasun, and P. de S. Gonçalves. 2005. "Yielding Potential of Rubber (Hevea brasiliensis) in Sub-Optimal Environments.” Journal of Crop Improvement 14(1-2):221-247. 
Roumasset, J., J. M. Boussard, and I. Singh, eds. 1979. Risk and Agricultural Development. College, Laguna, Philippines: Southeast Asian Regional Center for Graduate Study and Research in Agriculture.

Turnovsky, S. J. 1983. “The Determination of Spot and Futures Prices with Storable Commodities." Econometrica 51:1363-1387.

Turnovsky, S. J., and R. B. Campbell. 1985. "The Stabilizing and Welfare Properties of Futures Markets: A Simulation Approach.” International Economic Review 26:277-303.

United Nations, Conference on Trade and Development. 1998. A Survey of Commodity Risk Management Instruments. UNCTAD/COM/15/Rev.2. Geneva: United Nations Conference on Trade and Development. 1994. Report of the Ad-Hoc Group of Experts on Risk Management in Commodity Trade. TD/B/CN.1/22, TD/B/CN.1/GE.1/4. Geneva: United Nations Conference on Trade and Development.

United Nations, Food and Agriculture Organization (FAO). FAOSTAT Statistical Database. Available at http://faostat.fao.org/site/291/default.aspx (accessed September 5, 2007). Williams, J. C. 2001. “Commodity Futures and Options.” In B. L. Gardner and G. C. Rausser, eds. Handbook of Agricultural Economics, Volume 1b: Marketing, Distribution and Consumers. Amsterdam, Netherlands: Elsevier Science B.V.

Williams, J. C., and B. D. Wright. 1991. Storage and Commodity Markets. New York: Cambridge University Press.

World Trade Organization. 2004. World Trade Organization Agricultural Negotiations: Backgrounder - Updated December 1, 2004. Available at http://www.wto.org/english/ tratop_e/agric_e/negs_bkgrnd00_contents_e.htm (accessed September 5, 2007).

Zant, W. 2001. "Hedging Price Risks of Farmers by Commodity Boards: A Simulation Applied to the Indian Natural Rubber Market." World Development 29:691-710. 
Table 1. Parameter Values Corresponding to Natural Rubber Market Simulations

\begin{tabular}{|c|c|c|}
\hline \multicolumn{2}{|c|}{ Parameter } & Source \\
\hline Demand: & $\delta_{0}=1$ & Imposed by scaling convention. \\
\hline & $\delta_{1}=0.25$ & Based on Burger and Smit (2001). ${ }^{\mathrm{a}}$ \\
\hline Absolute Risk Aversion: & $\lambda_{j}=4.7, j=A, N$ & Zant (2001, p. 700). ${ }^{\mathrm{b}}$ \\
\hline \multirow[t]{2}{*}{ Production Cost: } & $\theta_{j, 0}=1 / \theta_{j, 1}, j=A, N$ & Imposed by scaling convention. \\
\hline & $\theta_{j, 1}=2, j=A, N$ & Zant (2001, p. 696). \\
\hline \multirow[t]{2}{*}{ Storage Cost: } & $\phi=0.009$ & Dealers' quarterly storage costs \\
\hline & & reported in Zant (2001, p. 700). \\
\hline Interest Rate: & $r=0.015$ & Zant 2001 (p. 709). \\
\hline \multirow[t]{2}{*}{ Demand Shocks: } & $\operatorname{Mean}\left(\varepsilon_{C, t}\right)=1, j=A, N$ & Imposed by definition. \\
\hline & $\operatorname{StD}\left(\varepsilon_{C, t}\right)=0.158, j=A, N$ & Obtained by calibration. $^{\mathrm{c}}$ \\
\hline \multirow[t]{3}{*}{ Output Shocks: } & $\operatorname{Mean}\left(\varepsilon_{q j, t}\right)=1, j=A, N$ & Imposed by definition. \\
\hline & $\operatorname{StD}\left(\varepsilon_{q j, t}\right)=0.07, j=A, N$ & Smallest coefficient of variation $(\mathrm{CV})$ \\
\hline & & in Table 3 of Priyadarshan et al. (2005). \\
\hline \multirow[t]{3}{*}{ Price-Transmission Shocks: } & $\operatorname{Mean}\left(\varepsilon_{p j, t}\right)=1, j=A, N$ & Imposed by scaling convention. \\
\hline & $\operatorname{StD}\left(\varepsilon_{p j, t}\right)=0.167, j=A, N$ & Required for $\operatorname{Corr}\left(P_{t}, p_{j, t}\right)=0.8$ as \\
\hline & & reported in ITF (2001, p. 17). ${ }^{d}$ \\
\hline
\end{tabular}

${ }^{\mathrm{a}}$ Burger and Smit (2001) report demand elasticity equal to 0.05 from monthly data. Given the observation period of one quarter used here, the demand elasticity is increased to $\delta_{1}=0.25$.

${ }^{\mathrm{b}}$ Zant (2001, p. 700) uses $\lambda_{j}=3.1 / \operatorname{Mean}\left(\pi_{\mathrm{j}, t}\right)$. Here, $\lambda_{j}=3.1 / 0.66=4.7$ because Mean $\left(\pi_{j, t}\right)=0.66$ for the scenarios without futures (see tables 3 and 4 below).

${ }^{\mathrm{c}}$ The data in Zant $\left(2001\right.$, p. 709) implies $C V\left(P_{t}\right) \equiv \operatorname{StD}\left(P_{t}\right) /$ Mean $\left(P_{t}\right)$ equal to $23 \%(=[0.000272353 /(1-$ $\left.\left.\left.0.813645^{2}\right)\right]^{0.5} /[0.023216 /(1-0.813645)]\right)$. $S t D\left(\varepsilon_{C, t}\right)$ is calibrated so as to yield $C V\left(P_{t}\right)=23 \%$ for the scenarios without futures (see tables 3 and 4 below).

${ }^{\mathrm{d}} \operatorname{Corr}\left(P_{t}, p_{j, t}\right)$ denotes the correlation between $P_{t}$ and $p_{j, t}$. For arbitrary independent random variables $y$ and $z$ with Mean $(y)>0$ and Mean $(z)=1$, it can be shown that $\operatorname{Corr}(y, y z)=\left\{1+\left(1+[C V(y)]^{-2}\right)\right.$ $\left.[\operatorname{StD}(z)]^{2}\right\}^{-1 / 2}$. For $\operatorname{Corr}\left(P_{t}, P_{t} \varepsilon_{p j, t}\right)=0.8$ and $C V\left(P_{t}\right)=23 \%$, this implies $\operatorname{StD}\left(\varepsilon_{p j, t}\right)=0.167$. 
Table 2. Steady-State Statistics for Market-Level Endogenous Random Variables

\begin{tabular}{|c|c|c|c|c|}
\hline & \multicolumn{2}{|c|}{$\begin{array}{l}\text { Small Share of Adopting Farmers } \\
\qquad\left(n_{A}=0.1, n_{N}=0.9\right)\end{array}$} & \multicolumn{2}{|c|}{$\begin{array}{l}\text { Large Share of Adopting Farmers } \\
\qquad\left(n_{A}=0.75, n_{N}=0.25\right)\end{array}$} \\
\hline & $\begin{array}{l}\text { Futures Not Available } \\
\qquad\left(\times 10^{-2}\right) \\
\end{array}$ & $\begin{array}{l}\text { Futures Available } \\
\qquad\left(\times 10^{-2}\right) \\
\end{array}$ & $\begin{array}{l}\text { Futures Not Available } \\
\qquad\left(\times 10^{-2}\right) \\
\end{array}$ & $\begin{array}{l}\text { Futures Available } \\
\qquad\left(\times 10^{-2}\right) \\
\end{array}$ \\
\hline Total Output $\left(n_{A} q_{A, t}+n_{N} q_{N, t}\right)$ & $\begin{array}{c}96.7(8.3) \\
{[83.3,96.6,110.3]}\end{array}$ & $\begin{array}{c}96.8(8.4) \\
{[83.3,96.6,110.6]}\end{array}$ & $\begin{array}{c}96.7(7.7) \\
{[84.2,96.6,109.0]}\end{array}$ & $\begin{array}{c}97.2(8.4) \\
{[84.1,96.8,111.3]}\end{array}$ \\
\hline Total Supply $\left(n_{A} q_{A, t}+n_{N} q_{N, t}+I_{t}\right)$ & $\begin{array}{c}143.9(54.5) \\
{[93.1,135.1,216.3]}\end{array}$ & $\begin{array}{c}143.6(54.1) \\
{[93.3,134.9,215.2]}\end{array}$ & $\begin{array}{c}143.0(54.0) \\
{[93.0,134.3,214.3]}\end{array}$ & $\begin{array}{c}141.4(52.1) \\
{[94.0,133.1,208.4]}\end{array}$ \\
\hline Current Consumption $\left(C_{t}\right)$ & $\begin{array}{c}96.7(3.8) \\
{[91.4,97.3,101.0]}\end{array}$ & $\begin{array}{c}96.8(3.7) \\
{[91.8,97.4,101.0]}\end{array}$ & $\begin{array}{c}96.7(3.8) \\
{[91.4,97.3,100.9]}\end{array}$ & $\begin{array}{c}97.2(3.5) \\
{[93.0,97.7,101.0]}\end{array}$ \\
\hline Storage $\left(I_{t+1}\right)$ & $\begin{array}{c}47.2(51.9) \\
{[1.6,37.8,115.3]}\end{array}$ & $\begin{array}{c}46.8(51.6) \\
{[1.5,37.5,114.2]}\end{array}$ & $\begin{array}{c}46.3(51.5) \\
{[1.5,37.0,113.3]}\end{array}$ & $\begin{array}{c}44.2(49.8) \\
{[1.0,35.4,107.4]}\end{array}$ \\
\hline World Price $\left(P_{t}\right)$ & $\begin{array}{c}116.5(27.0) \\
{[96.2,111.5,143.0]}\end{array}$ & $\begin{array}{c}116.0(26.4) \\
{[96.1,111.1,141.1]}\end{array}$ & $\begin{array}{c}116.7(26.8) \\
{[96.4,111.8,143.3]}\end{array}$ & $\begin{array}{c}113.9(23.8) \\
{[95.9,109.7,133.4]}\end{array}$ \\
\hline Consumption Expenditures $\left(P_{t} C_{t}\right)$ & $\begin{array}{c}111.7(17.4) \\
{[97.1,108.5,130.8]}\end{array}$ & $\begin{array}{c}111.4(17.0) \\
{[97.0,108.2,129.5]}\end{array}$ & $\begin{array}{c}111.9(17.3) \\
{[97.3,108.7,131.0]}\end{array}$ & $\begin{array}{c}109.9(15.5) \\
{[96.9,107.2,124.2]}\end{array}$ \\
\hline
\end{tabular}

Note: Stand-alone numbers denote means, numbers within parentheses are standard deviations, and the three numbers within brackets are, respectively, the 5 percent quantile, the median, and the 95 percent quantile. Unconditional pdfs are based on the Monte Carlo simulation of 25,000 time series of 2,000 observations each. To avoid dependence on initial conditions, the first 1,000 observations from each series are discarded. The reported unconditional point statistics are estimated from a total of $2.5 \times 10^{7}$ simulated observations, so that the number of reported digits is consistent with an estimated confidence level of at least 95\%. Antithetic acceleration (Geweke 1988) is used to improve efficiency, and "common random numbers" are employed to enhance accuracy in the comparison across alternative scenarios (i.e., all scenarios are based on the same simulated series of exogenous random variables). 
Table 3. Steady-State Statistics for Endogenous Random Variables Corresponding to Adopting Farmers

\begin{tabular}{|c|c|c|c|c|}
\hline & \multicolumn{2}{|c|}{$\begin{array}{l}\text { Small Share of Adopting Farmers } \\
\qquad\left(n_{A}=0.1, n_{N}=0.9\right)\end{array}$} & \multicolumn{2}{|c|}{$\begin{array}{l}\text { Large Share of Adopting Farmers } \\
\qquad\left(n_{A}=0.75, n_{N}=0.25\right)\end{array}$} \\
\hline & $\begin{array}{l}\text { Futures Not Available } \\
\qquad\left(\times 10^{-2}\right)\end{array}$ & $\begin{array}{l}\text { Futures Available } \\
\qquad\left(\times 10^{-2}\right)\end{array}$ & $\begin{array}{l}\text { Futures Not Available } \\
\qquad\left(\times 10^{-2}\right)\end{array}$ & $\begin{array}{l}\text { Futures Available } \\
\qquad\left(\times 10^{-2}\right)\end{array}$ \\
\hline Planned Output $\left(x_{A, t}\right)$ & $\begin{array}{c}95.9(5.3) \\
{[87.0,96.4,103.7]}\end{array}$ & $\begin{array}{c}99.1(8.3) \\
{[87.5,98.0,116.0]}\end{array}$ & $\begin{array}{c}96.7(5.6) \\
{[87.4,97.1,105.3]}\end{array}$ & $\begin{array}{c}97.8(7.1) \\
{[87.4,97.0,111.4]}\end{array}$ \\
\hline Actual Output $\left(q_{A, t}\right)$ & $\begin{array}{c}95.9(8.5) \\
{[82.3,95.8,110.0]}\end{array}$ & $\begin{array}{c}99.1(10.8) \\
{[83.0,98.2,118.3]}\end{array}$ & $\begin{array}{c}96.7(8.8) \\
{[82.7,96.6,111.2]}\end{array}$ & $\begin{array}{c}97.8(9.9) \\
{[82.7,97.3,114.9]}\end{array}$ \\
\hline Hedging $\left(h_{A, t}\right)$ & & $\begin{array}{c}81.3(3.6) \\
{[75.5,81.9,87.5]}\end{array}$ & & $\begin{array}{c}66.9(6.1) \\
{[59.1,65.5,79.4]}\end{array}$ \\
\hline Local Crop Price $\left(p_{A, t}\right)$ & $\begin{array}{c}116.5(33.6) \\
{[80.5,111.4,163.8]}\end{array}$ & $\begin{array}{c}116.0(33.0) \\
{[80.4,111.1,162.6]}\end{array}$ & $\begin{array}{c}116.7(33.4) \\
{[80.7,111.7,164.2]}\end{array}$ & $\begin{array}{c}113.9(30.7) \\
{[79.8,109.5,157.6]}\end{array}$ \\
\hline Crop Profits $\left[p_{A, t} q_{A, t}-v_{A}\left(x_{A, t-1}\right)\right]$ & $\begin{array}{c}66.3(34.5) \\
{[29.9,60.6,115.9]}\end{array}$ & $\begin{array}{c}66.5(36.2) \\
{[29.4,60.4,118.0]}\end{array}$ & $\begin{array}{c}66.4(33.2) \\
{[30.5,61.1,115.0]}\end{array}$ & $\begin{array}{c}63.9(31.2) \\
{[29.5,59.0,109.6]}\end{array}$ \\
\hline Hedging Profits $\left[\left(F_{t-1}-P_{t}\right) h_{A, t}\right]$ & & $\begin{array}{c}0.0(19.7) \\
{[-15.7,1.8,17.7]}\end{array}$ & & $\begin{array}{c}0.0(15.9) \\
{[-10.9,1.5,13.9]}\end{array}$ \\
\hline Total Profits (Crop Prof. + Hedging Prof.) & $\begin{array}{c}66.3(34.5) \\
{[29.9,60.6,115.9]}\end{array}$ & $\begin{array}{c}66.5(26.9) \\
{[31.4,62.7,114.2]}\end{array}$ & $\begin{array}{c}66.4(33.2) \\
{[30.5,61.1,115.0]}\end{array}$ & $\begin{array}{c}63.9(24.3) \\
{[30.9,60.8,106.9]}\end{array}$ \\
\hline
\end{tabular}

Note: Stand-alone numbers denote means, numbers within parentheses are standard deviations, and the three numbers within brackets are, respectively, the 5 percent quantile, the median, and the 95 percent quantile. Unconditional pdfs are based on the Monte Carlo simulation of 25,000 time series of 2,000 observations each. To avoid dependence on initial conditions, the first 1,000 observations from each series are discarded. The reported unconditional point statistics are estimated from a total of $2.5 \times 10^{7}$ simulated observations, so that the number of reported digits is consistent with an estimated confidence level of at least 95\%. Antithetic acceleration (Geweke 1988) is used to improve efficiency, and "common random numbers" are employed to enhance accuracy in the comparison across alternative scenarios (i.e., all scenarios are based on the same simulated series of exogenous random variables). 
Table 4. Steady-State Statistics for Endogenous Random Variables Corresponding to Non-Adopting Farmers

\begin{tabular}{|c|c|c|c|c|}
\hline & \multicolumn{2}{|c|}{$\begin{array}{l}\text { Small Share of Adopting Farmers } \\
\qquad\left(n_{A}=0.1, n_{N}=0.9\right)\end{array}$} & \multicolumn{2}{|c|}{$\begin{array}{l}\text { Large Share of Adopting Farmers } \\
\qquad\left(n_{A}=0.75, n_{N}=0.25\right)\end{array}$} \\
\hline & $\begin{array}{l}\text { Futures Not Available } \\
\qquad\left(\times 10^{-2}\right)\end{array}$ & $\begin{array}{l}\text { Futures Available } \\
\qquad\left(\times 10^{-2}\right)\end{array}$ & $\begin{array}{l}\text { Futures Not Available } \\
\qquad\left(\times 10^{-2}\right)\end{array}$ & $\begin{array}{l}\text { Futures Available } \\
\qquad\left(\times 10^{-2}\right)\end{array}$ \\
\hline Planned Output $\left(x_{N, t}\right)$ & $\begin{array}{c}96.7(5.7) \\
{[87.2,97.1,105.4]}\end{array}$ & $\begin{array}{c}96.4(5.5) \\
{[87.2,96.8,104.8]}\end{array}$ & $\begin{array}{c}96.2(5.3) \\
{[87.2,96.6,104.2]}\end{array}$ & $\begin{array}{c}94.9(4.6) \\
{[86.9,95.6,101.0]}\end{array}$ \\
\hline Actual Output $\left(q_{N, t}\right)$ & $\begin{array}{c}96.7(8.8) \\
{[82.6,96.6,111.3]}\end{array}$ & $\begin{array}{c}96.4(8.7) \\
{[82.6,96.3,110.9]}\end{array}$ & $\begin{array}{c}96.2(8.6) \\
{[82.5,96.1,110.4]}\end{array}$ & $\begin{array}{c}94.9(8.1) \\
{[82.0,94.8,108.2]}\end{array}$ \\
\hline Local Crop Price $\left(p_{N, t}\right)$ & $\begin{array}{c}116.5(33.6) \\
{[80.5,111.4,163.8]}\end{array}$ & $\begin{array}{c}116.0(33.0) \\
{[80.4,111.1,162.6]}\end{array}$ & $\begin{array}{c}116.7(33.4) \\
{[80.7,111.7,164.2]}\end{array}$ & $\begin{array}{c}113.9(30.7) \\
{[79.8,109.5,157.6]}\end{array}$ \\
\hline Profits $\left[p_{N, t} q_{N, t}-v_{N}\left(x_{N, t-1}\right)\right]$ & $\begin{array}{c}66.2(33.0) \\
{[30.5,60.9,114.4]}\end{array}$ & $\begin{array}{c}65.6(32.4) \\
{[30.3,60.5,112.9]}\end{array}$ & $\begin{array}{c}66.5(34.1) \\
{[30.2,60.9,116.0]}\end{array}$ & $\begin{array}{c}63.4(30.7) \\
{[29.4,58.7,108.3]}\end{array}$ \\
\hline
\end{tabular}

Note: Stand-alone numbers denote means, numbers within parentheses are standard deviations, and the three numbers within brackets are, respectively, the 5 percent quantile, the median, and the 95 percent quantile. Unconditional pdfs are based on the Monte Carlo simulation of 25,000 time series of 2,000 observations each. To avoid dependence on initial conditions, the first 1,000 observations from each series are discarded. The reported unconditional point statistics are estimated from a total of $2.5 \times 10^{7}$ simulated observations, so that the number of reported digits is consistent with an estimated confidence level of at least 95\%. Antithetic acceleration (Geweke 1988) is used to improve efficiency, and "common random numbers" are employed to enhance accuracy in the comparison across alternative scenarios (i.e., all scenarios are based on the same simulated series of exogenous random variables). 


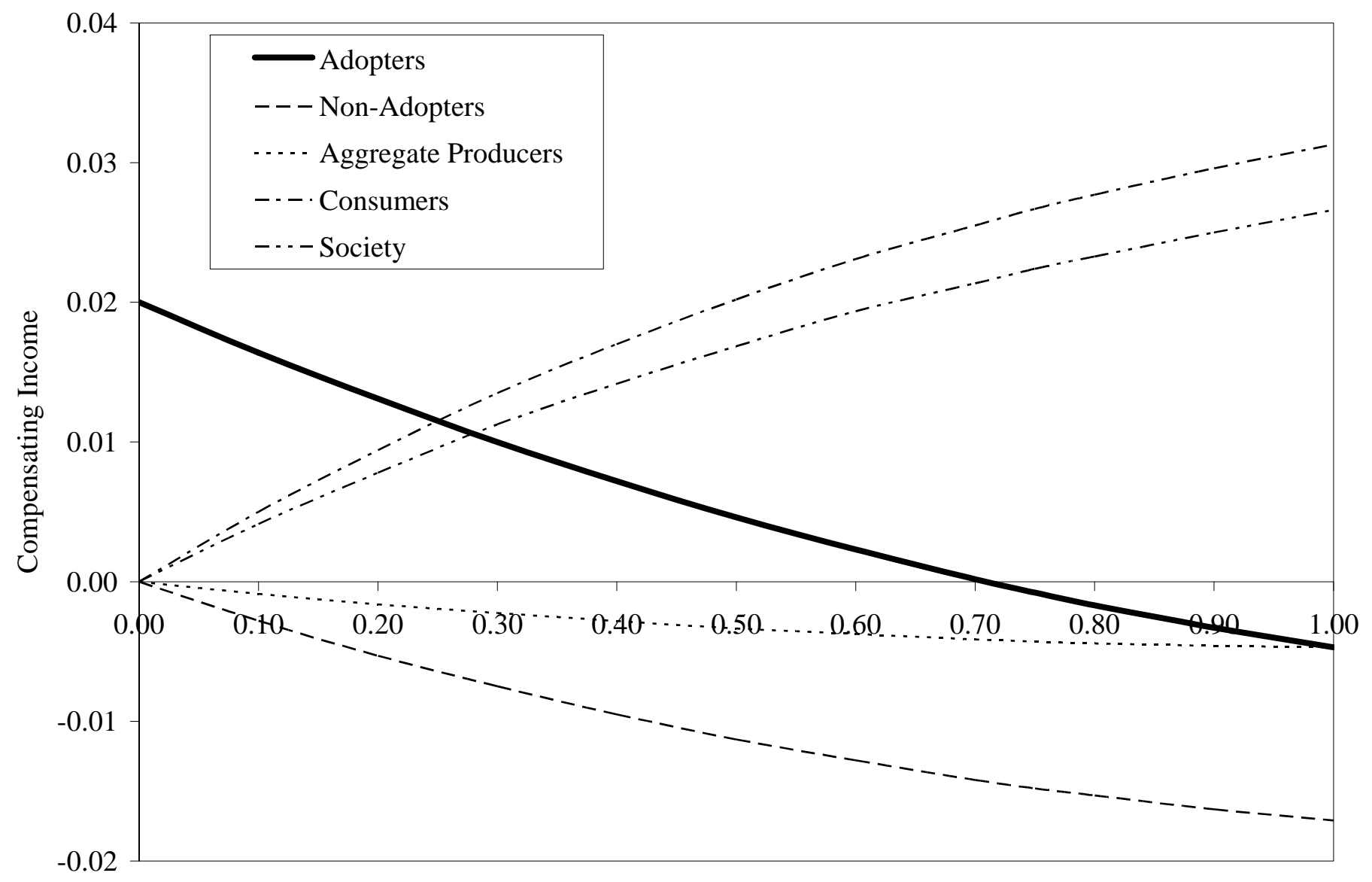

Share of Farmers Adopting Futures $\left(n_{A}\right)$

\section{Figure 1. Compensating Incomes Associated with Futures Availability}

Note: To put the magnitudes of compensating income in perspective, note that when futures are not available median consumption expenditures are about 1.086 (see last row of table 2), median profits for adopting farmers are around 0.608 (see last row of table 3), and median profits for non-adopting farmers are approximately 0.609 (see last row of table 4). 